\title{
Point defects in silicon after zinc diffusion-a deep level transient spectroscopy and spreading-resistance profiling study
}

\author{
A Masuhr $\dagger, \mathrm{H}$ Bracht $\ddagger$, N A Stolwijk $\ddagger$ H Overhof $\S$ and H Mehrer $\ddagger$ \\ $\dagger$ Department of Materials Science, California Institute of Technology, Pasadena, CA 91125, \\ USA \\ ‡ Institut für Metallforschung, Westfälische Wilhelms-Universität Münster, \\ Wilhelm-Klemm-Strasse 10, Germany \\ $\S$ Universität-Gesamthochschule Paderborn, Warburger Strasse 100, 33098 Paderborn, \\ Germany
}

Received 3 April 1998, accepted for publication 4 January 1999

\begin{abstract}
We present results from spreading-resistance profiling and deep level transient spectroscopy on $\mathrm{Si}$ after $\mathrm{Zn}$ diffusion at $1294 \mathrm{~K}$. Concentration profiles of substitutional $\mathrm{Zn}_{s}$ in dislocation-free and highly dislocated $\mathrm{Si}$ are described by a diffusion mechanism involving interstitial-substitutional exchange. Additional annealing at $873 \mathrm{~K}$ following quenching from the diffusion temperature is required in the case of dislocation-free $\mathrm{Si}$ to electrically activate $\mathrm{Zn}_{s}$. The formation of complexes of $\mathrm{Zn}_{s}$ with unwanted impurities upon quenching is discussed. Additional Ni diffusion experiments as well as total energy calculations suggest that $\mathrm{Ni}$ is a likely candidate for the passivation of $\mathrm{Zn}_{s}$. From total energy calculations we find that the formation of complexes involving $\mathrm{Zn}$ and $\mathrm{Ni}$ depends on the position of the Fermi level. This explains differences in results from spreading-resistance profiling and deep level transient spectroscopy on near-intrinsic and p-type $\mathrm{Si}$, respectively.
\end{abstract}

\section{Introduction}

Foreign-atom diffusion in Si has been extensively studied in the past [1]. Among the elements investigated, $\mathrm{Zn}$ has recently found particular interest [2-4]. Zn diffusion in $\mathrm{Si}$ is known to be governed by an interstitial-substitutional exchange mechanism involving fast diffusing interstitial $\mathrm{Zn}_{i}$ and relatively immobile substitutional $\mathrm{Zn}_{s}$ as well as Si selfinterstitials, $\mathrm{Si}_{i}$. It has been demonstrated [4] that it is possible to deduce information about the mobility of $\mathrm{Si}_{i}$ from the time and temperature dependence of the $\mathrm{Zn}$ distribution in $\mathrm{Si}$. This analysis requires a detailed understanding of the various defects mediating diffusion. Moreover, during the quenching process subsequent to the diffusion anneal, point defect reactions may occur and complicate the analysis of the $\mathrm{Zn}$ profiles. Among possible unintentionally introduced impurities and potential candidates for these point defect reactions in $\mathrm{Si}$ we will focus on $\mathrm{Ni}$ in the following.

Spreading-resistance profiling (SRP) plays a major role among the experimental tools used in the study of foreign-atom diffusion. It allows us to efficiently sample a large number of electrical-resistance profiles resulting from the in-diffusion under various annealing conditions. However, the local configuration of the point defects present after quenching from the diffusion temperature and the corresponding energy levels have to be known or assumed in order to calculate accurate concentration profiles from SRP measurements. Point defect reactions during quenching or the presence of unwanted impurities can further complicate this procedure. Likely contaminants are $\mathrm{Ni}, \mathrm{Cu}, \mathrm{Fe}$ and $\mathrm{Cr}$ because they are common constituents of heat-coil resistance wires used in conventional furnaces and may penetrate due to their small size through the walls of the quartz ampoules used for high temperature diffusion annealing. Additional annealing steps may be necessary to obtain reproducible profiles.

In this work we analyse Zn-diffused Si both by SRP and by spatially resolved deep level transient spectroscopy (DLTS). The spectroscopic nature of the DLTS measurements allows for a direct check of the validity of the assumptions necessary for converting spreading-resistance profiles into $\mathrm{Zn}$ concentration profiles. These assumptions concern the position of the predominant $\mathrm{Zn}$-related energy levels within the Si band gap. Differences between the results from the two experimental techniques will be discussed in terms of formation of complexes of $\mathrm{Zn}$ with unwanted impurities. For this purpose our Zn-diffused samples were deliberately contaminated with $\mathrm{Ni}$, as a typical impurity present in furnace environments. In addition, we performed total energy calculations on $\mathrm{Zn}-\mathrm{Ni}$ complex formation. 


\section{Experiment}

For the SRP measurements near-intrinsic $\left(10^{4} \Omega \mathrm{cm}\right.$, n-type $)$ floating-zone $\mathrm{Si}$ was used while DLTS measurements were performed on p-type floating-zone $\mathrm{Si}(2 \Omega \mathrm{cm})$. Both dislocation-free samples and plastically deformed samples with dislocation densities of more than $10^{8} \mathrm{~cm}^{-2}$ were employed. The samples were cut typically to $8 \times 8 \times 1 \mathrm{~mm}^{3}$, mechanically and chemically polished, and placed in fused silica ampoules. Elemental Zn (99.999\%) was added to give $\mathrm{Zn}$ vapour pressures of about $1 \mathrm{~atm}$ at the diffusion temperature. The ampoules were mounted in a vertical resistance furnace at $1294 \mathrm{~K}$ for $20 \mathrm{~min}$ and subsequently quenched in ethylene glycol.

For SRP a cross-section of the sample was lapped and diamond polished. The SRP probe-to-sample contact resistance was accounted for by calibration measurements. Details of the procedure can be found elsewhere [5].

The Zn-diffused DLTS samples were bevelled to $4^{\circ}$ prior to chemical polishing with $\mathrm{HF}, \mathrm{HNO}_{3}$ and $\mathrm{HCl}$. Subsequently, a grid of circular Al contacts of $0.8 \mathrm{~mm}$ diameter and $0.5 \mathrm{~mm}$ spacing was evaporated on the bevelled front side to allow for spatially resolved detection of deep levels on a single sample. Ohmic contacts were prepared by evaporating Au on the backside of the samples. The diode characteristics were checked to yield low leakage currents of less than $10^{-8}$ A. Capacitancevoltage measurements accurately reproduced the boron concentration of the as-received material.

DLTS scans were carried out from $80 \mathrm{~K}$ to $400 \mathrm{~K}$ with bias and pulse voltages of $4 \mathrm{~V}$ and $1 \mathrm{~V}$, respectively. The capacitance relaxation curves $C(t, T)$ were sampled at a frequency of $10^{4} \mathrm{~Hz}$ for $5 \times 10^{-2} \mathrm{~s}$ each. About 400 transients were averaged per temperature interval of $1 \mathrm{~K}$. A numerical lock-in analysis

$$
S(T)=-\frac{1}{P} \int_{0}^{P} C(t, T) \sin \left(\frac{2 \pi t}{P}\right) \mathrm{d} t
$$

was used to calculate DLTS spectra $S(T)$ with integration times $P$ from $1 \times 10^{-3} \mathrm{~s}$ to $5 \times 10^{-2} \mathrm{~s}$. Accordingly, hole emission coefficients $e_{p}$ of deep levels at the maxima of the DLTS peaks, $T_{\max }$, were calculated by $e_{p}\left(T_{\max }\right)$ $=(0.42435 P)^{-1}$ and the temperature dependence of $e_{p}$ was analysed as [6]

$$
e_{p}(T)=\sigma_{P}^{*} v_{t h, p}(T) N_{v}(T) \exp \left(-\frac{\Delta H}{k_{B} T}\right) .
$$

A temperature-dependent effective mass [7] was considered in the temperature dependence of the average thermal velocity of electron holes, $v_{t h, p}(T)$, and the effective density of states at the valence band edge, $N_{v}(T)$. In contrast, a temperature-independent capture cross section $\sigma_{P}^{*}$ is assumed for all defects, as the experimental setup used in the present study does not allow for its direct measurement.

\section{Experimental results}

DLTS spectra after Zn diffusion into dislocation-rich silicon for various penetration depths are shown in figure 1 .

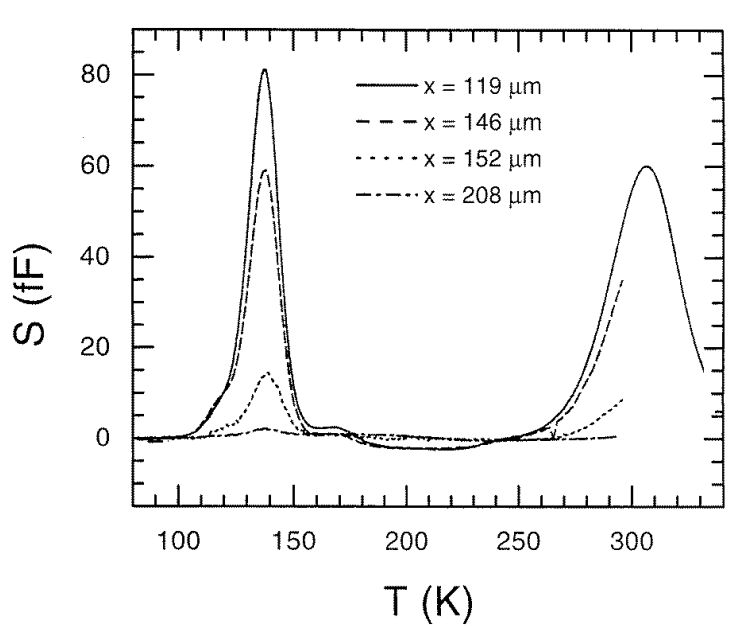

Figure 1. DLTS spectra after $\mathrm{Zn}$ diffusion in dislocation-rich $\mathrm{Si}$ at $1294 \mathrm{~K}$ as recorded at various depths $x$.

Table 1. Parameters characterizing DLTS-resolved defects in $\mathrm{Si}$ after $\mathrm{Zn}$ diffusion.

\begin{tabular}{lrll}
\hline & $T_{\max }(\mathrm{K})$ & $\Delta H(\mathrm{eV})$ & $\sigma_{P}^{*}\left(\mathrm{~m}^{2}\right)$ \\
\hline $\mathrm{Zn}_{s}^{0 /-}$ & 137 & 0.28 & $8.6 \times 10^{-19}$ \\
$\mathrm{Zn}_{s}^{-/ 2-}$ & 301 & 0.58 & $4.9 \times 10^{-20}$ \\
$\mathrm{ZnX1}$ & 118 & 0.21 & $8.9 \times 10^{-20}$ \\
$\mathrm{ZnX2}$ & 167 & 0.32 & $2.7 \times 10^{-19}$ \\
$\mathrm{~A} 1$ & 93 & 0.17 & $2.4 \times 10^{-19}$ \\
$\mathrm{~A} 2$ & 126 & 0.26 & $1.0 \times 10^{-18}$ \\
$\mathrm{~A} 3$ & 235 & 0.47 & $2.4 \times 10^{-19}$ \\
$\mathrm{~A} 4$ & 265 & 0.60 & $3.1 \times 10^{-18}$ \\
\hline
\end{tabular}

The spectra are plotted in units of $10^{-15} \mathrm{~F}(\mathrm{fF})$. The two main peaks at $140 \mathrm{~K}$ and $310 \mathrm{~K}$ are in good agreement with the double acceptor behaviour of $\mathrm{Zn}_{s}$ in $\mathrm{Si}[8,9]$ and will be referred to as $\mathrm{Zn}_{s}^{0 /-}$ and $\mathrm{Zn}_{s}^{-/ 2-}$. In particular, the corresponding defect state concentrations are found to be mutually equal within $20 \%$. Energy levels $\Delta H$ and effective capture cross sections $\sigma_{p}^{*}$ are summarized in table 1 . The uncertainty in the energy levels observed by DLTS is less than $0.03 \mathrm{eV}$ and mainly stems from the limited knowledge about the temperature dependence of $\sigma_{p}^{*}$. For the same reason, the absolute values of $\sigma_{p}^{*}$ may vary by up to two orders of magnitude. Maximum temperatures, $T_{\max }$, in table 1 are reproducible within $\pm 1 \mathrm{~K}$ and correspond to spectra obtained with an integration time $P$ of $5 \times 10^{-2}$ s. A concentration analysis from the peak heights yields $\mathrm{Zn}_{s}$ concentrations as shown in figure 2. Also plotted in figure 2 is a complementary error function fit to the DLTS data (see section 4) and the SRP measurement on a near-intrinsic sample, which was diffused with $\mathrm{Zn}$ together with the sample used for DLTS.

DLTS spectra and concentration profiles obtained after $\mathrm{Zn}$ diffusion into dislocation-free samples at $1294 \mathrm{~K}$ and subsequent quenching are shown in figures 3 and 4 , respectively. In figure 4 open symbols represent concentrations of individual levels while the sums of all levels at each penetration depth are shown as solid symbols. All DLTS measurements shown in figure 4 were performed on the same sample. While the DLTS spectra on quenched dislocation-free $\mathrm{Si}$ are qualitatively reproducible, the spatial distribution of the detected defects varied among samples subject to the same diffusion treatment. 


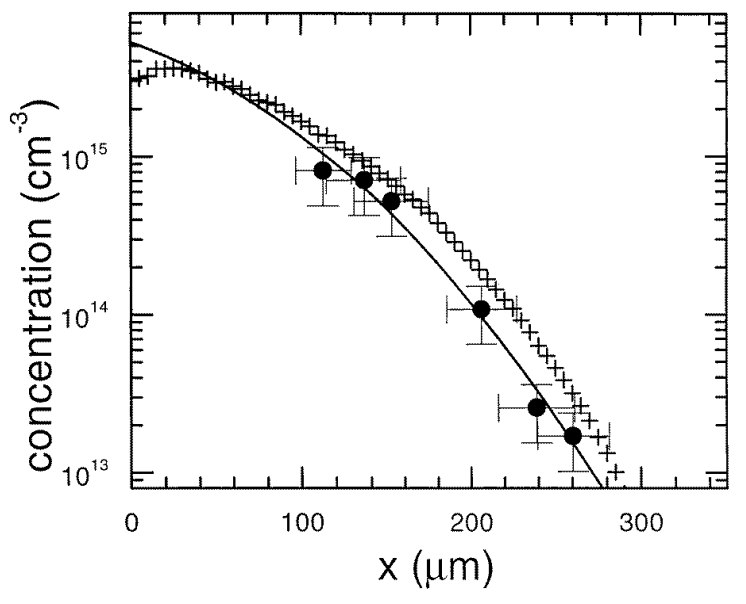

Figure 2. Concentration profiles of substitutional $\mathrm{Zn}$ in dislocation-rich $\mathrm{Si}$ after $\mathrm{Zn}$ diffusion at $1294 \mathrm{~K}$ from depth-resolved DLTS (๑) with corresponding fit of equation (2) (full curve) and from SRP (+).

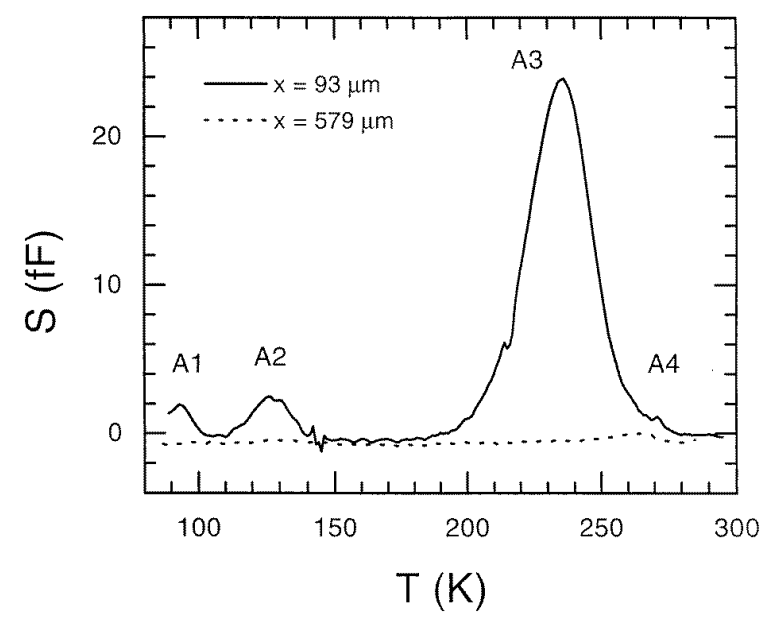

Figure 3. DLTS spectra after Zn diffusion at $1294 \mathrm{~K}$ in dislocation-free $\mathrm{Si}$ as recorded at various depths $x$.

After the $\mathrm{Zn}$ diffusion at $1294 \mathrm{~K}$ several samples were annealed at $873 \mathrm{~K}$ for $20 \mathrm{~min}$. Schottky contacts were prepared after the second heat treatment. Resulting spectra and profiles are presented in figures 5 and 6 , respectively. Simulated profiles of $\mathrm{Zn}_{s}, \mathrm{Zn}_{i}$ and $\mathrm{Si}_{i}$ resulting from a leastsquares fit to the SRP data are also shown. The calculations are based on the kick-out diffusion mechanism [4]

$$
\mathrm{Zn}_{i}+\mathrm{Si}_{s} \rightleftharpoons \mathrm{Zn}_{s}+\mathrm{Si}_{i}
$$

The concentration of substitutional $\mathrm{Si}, \mathrm{Si}_{s}$, is assumed to be constant at $5 \times 10^{22} \mathrm{~cm}^{-3}$ in the simulation.

To study the possible influence of metallic impurities in furnace environments on the observed defects after $\mathrm{Zn}$ diffusion Ni was chosen because of its high solubility as well as its fast diffusivity in $\mathrm{Si}$ [10]. To this aim $\mathrm{Ni}$ was evaporated on a Zn-diffused, as-quenched sample and subsequently annealed at $873 \mathrm{~K}$ for $20 \mathrm{~min}$. The DLTS spectra of sequentially $\mathrm{Zn}$ - and $\mathrm{Ni}$-diffused samples are shown in figure 7(a). Schottky contact preparation was performed

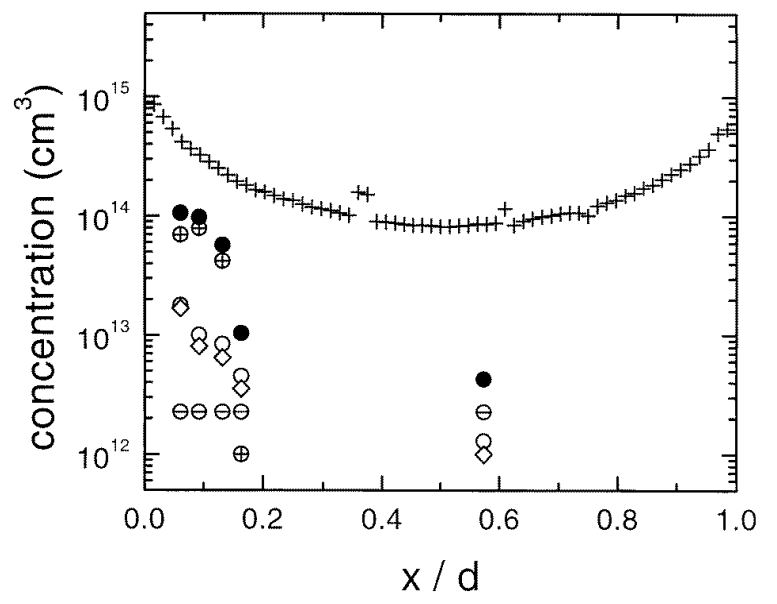

Figure 4. Concentration profiles of deep levels in dislocation-free $\mathrm{Si}$ after $\mathrm{Zn}$ diffusion at $1294 \mathrm{~K}$ from depth-resolved DLTS (open symbols: $\diamond, \mathrm{A} 1 ; \bigcirc, \mathrm{A} 2 ; \oplus, \mathrm{A} 3 ; \ominus, \mathrm{A} 4)$ and from SRP (+). Solid symbols $(\bullet)$ represent the sum of the concentrations obtained by DLTS for each depth. The depth, $x$, is normalized to the sample thickness, $d=1.008 \mathrm{~mm}$.

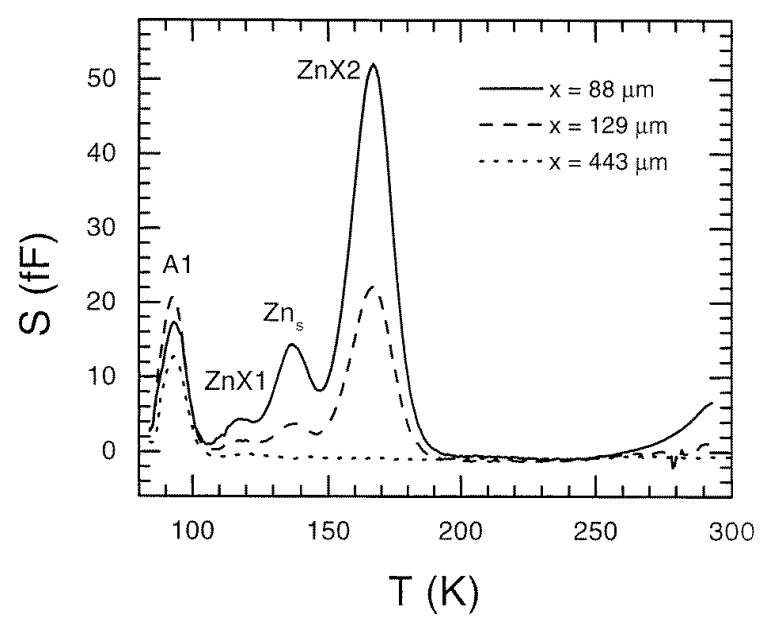

Figure 5. DLTS spectra after Zn diffusion at $1294 \mathrm{~K}$ in dislocation-free $\mathrm{Si}$ and subsequent annealing at $873 \mathrm{~K}$ as recorded at various depths $x$.

after the second annealing step. After this preparation it is possible to anneal the sample within the DLTS apparatus to temperatures up to $400 \mathrm{~K}$ without detrimental effects on the electrical properties of the contact. The sample diffused with both $\mathrm{Zn}$ and $\mathrm{Ni}$, not showing any peaks after the diffusion, was heated to $400 \mathrm{~K}$ for 3 hours. A reverse bias voltage of $4 \mathrm{~V}$ was applied to one of the contacts during the heat treatment; the others were not contacted. Resulting DLTS spectra are shown in figure 7(b).

\section{Discussion}

The two $\mathrm{Zn}$ levels of equal abundance shown in figure 1 and table 1 are attributed to the acceptor states $\mathrm{Zn}_{s}^{0 /-}$ and $\mathrm{Zn}_{s}^{-/ 2-}$ of substitutional $\mathrm{Zn}$, in agreement with the widely accepted arguments given in the literature $[3,8,9]$. The present ionization enthalpies are within 


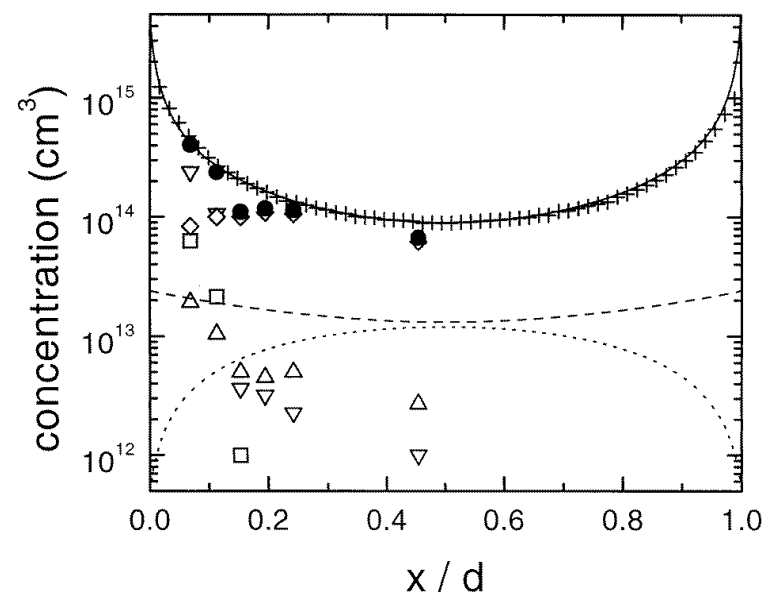

Figure 6. Concentration profiles of deep levels in dislocation-free $\mathrm{Si}$ after $\mathrm{Zn}$ diffusion at $1294 \mathrm{~K}$ and subsequent annealing at $873 \mathrm{~K}$ from depth-resolved DLTS (open symbols: $\diamond, \mathrm{A} 1 ; \triangle, \mathrm{ZnX} 1$; $\left.\nabla, \mathrm{ZnX} 2 ; \square, \mathrm{Zn}_{s}^{0 /-}\right)$ and $\operatorname{SRP}(+)$. Solid symbols $(\bullet)$ represent the sum of the concentrations obtained by DLTS for each depth. Simulated profiles of $\mathrm{Zn}_{s}$ (full curve), $\mathrm{Zn}_{i}$ (broken curve) and $\mathrm{Si}_{i}$ (chain curve) based on the kick-out mechanism are also shown. The depth, $x$, is normalized to the sample thickness, $d=0.984 \mathrm{~mm}$.

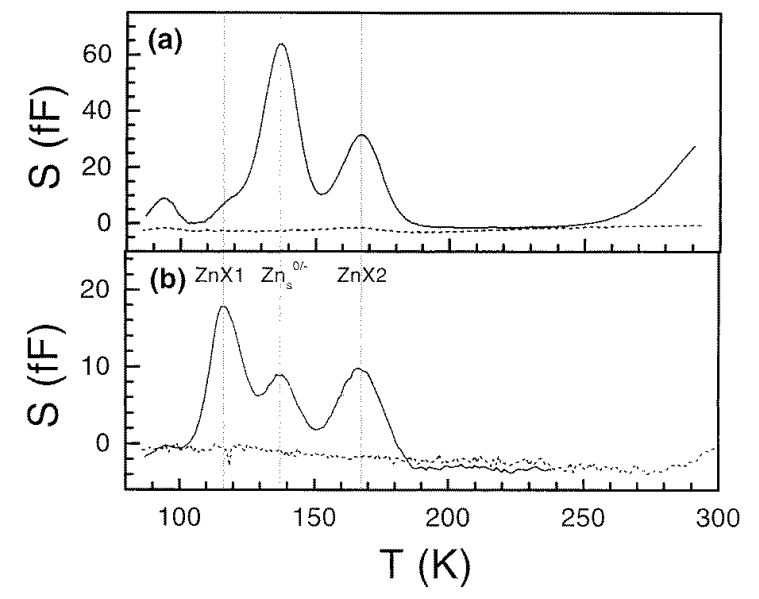

Figure 7. (a) DLTS spectra after Zn diffusion at $1294 \mathrm{~K}$ in dislocation-free $\mathrm{Si}$ and subsequent annealing at $873 \mathrm{~K}$ (full curve) and after $\mathrm{Zn}$ diffusion at $1294 \mathrm{~K}$ and subsequent $\mathrm{Ni}$ diffusion at $873 \mathrm{~K}$ (broken curve). (b) DLTS spectra after sequential Zn and Ni diffusion and additional annealing at $400 \mathrm{~K}$ with reverse bias voltage (full curve) and without bias voltage (broken curve). The vertical lines indicate the peak positions of the levels $\mathrm{ZnX1}, \mathrm{Zn}_{s}^{0 /-}$ and $\mathrm{ZnX} 2$.

the range spanned by previously reported values. Some variation in these values may be due to different assumptions concerning the temperature dependence of the capture cross section, the application of a PooleFrenkel correction, errors in the temperature measurement etc. This will not be further discussed here, since for the present work identification of defect states and determination of defect concentrations are more important than absolute specification of the corresponding electronic energies.

In plastically deformed $\mathrm{Si}$ dislocations serve as sinks for $\mathrm{Si}_{i}$ and the diffusion of $\mathrm{Zn}$ is controlled by the effective diffusivity $[2,10]$

$$
D_{Z n}^{e f f}=\frac{C_{Z n_{i}}^{e q}}{C_{Z n_{s}}^{e q}} D_{Z n_{i}}
$$

of $\mathrm{Zn}$. In equation (1) $D_{Z n_{i}}$ is the diffusivity of interstitial $\mathrm{Zn}_{i}$, and we have assumed, based on experimental evidence $[4,11,12]$, that the equilibrium concentration, $C_{Z n_{s}}^{e q}$, of substitutional $\mathrm{Zn}_{s}$ is large compared to the concentration, $C_{Z n_{i}}^{e q}$, of interstitial $\mathrm{Zn}_{i}$. From a least-squares fit of the complementary error function

$$
C_{Z n_{s}}(x, t)=C_{Z n_{s}}^{e q} \operatorname{erfc}\left(\frac{x}{2 \sqrt{D_{Z n}^{e f f} t}}\right)
$$

to the concentration profile resulting from depth-resolved DLTS in figure 2 we obtain $C_{Z n_{s}}^{e q}=(5.3 \pm 1.0) \times 10^{15} \mathrm{~cm}^{-3}$ and $D_{Z n}^{e f f}=(3.2 \pm 1.0) \times 10^{-6} \mathrm{~cm}^{2} \mathrm{~s}^{-1}$. These parameter values are in satisfactory agreement with previously published results from neutron-activation analysis [4] and SRP [12] of $C_{Z n_{s}}^{e q}=9.5 \times 10^{15} \mathrm{~cm}^{-3}$ and $D_{Z n}^{e f f}=4.0 \times 10^{-6} \mathrm{~cm}^{2} \mathrm{~s}^{-1}$.

Transition metal impurities like $\mathrm{Cu}, \mathrm{Ni}, \mathrm{Fe}$ or $\mathrm{Cr}$ may be introduced unintentionally during the high temperature anneal, the more so since these elements are usually contained in the heat coils of resistance wire furnaces used for the present experiments. However, DLTS and SRP data obtained from the analysis of $\mathrm{Zn}$-diffused dislocation-rich Si appear to be not affected by the incorporation of such impurities. This is very likely caused by the presence of dislocations, which provide effective sinks for unwanted impurities. The good agreement between the SRP and DLTS data in figure 1 and the absence of energy levels related to $\mathrm{Zn}-\mathrm{B}$ complexes like, e.g., A1 (see below) strongly indicate that trapping of $\mathrm{Zn}$ by $\mathrm{B}$ atoms does not play a major role, neither as diffusion proceeds, nor during quenching. Furthermore, a doping effect of $\mathrm{B}$ on $\mathrm{Zn}$ diffusion can be ignored since at the diffusion temperature the intrinsic carrier density, $n_{i}$, exceeds the maximum $\mathrm{Zn}$ concentration by many orders of magnitude, i.e. $n_{i}(T) \gg C_{Z n_{s}}^{e q} \gg C_{Z n_{i}}^{e q}$.

In dislocation-free $\mathrm{Si}, \mathrm{Zn}_{s}$ is passivated upon cooling by impurity atoms probably introduced during the diffusion anneal. Immediately after quenching no $\mathrm{Zn}_{s}$ is detectable in the p-type DLTS samples as shown in figure 3. The concentration profile of the dominating peak, A3, in asquenched dislocation-free $\mathrm{Si}$ at $235 \mathrm{~K}$ is not correlated with the $\mathrm{Zn}_{s}$ profile as shown in figure 4 . From the present results it is yet unclear what the physical origin of this DLTSresolved defect state is. In contrast to the DLTS analysis, the SRP measurement of the near-intrinsic sample in figure 4 yields a profile that resembles the expected $\mathrm{Zn}_{s}$ distribution. This difference between DLTS and SRP points to dissimilar complex formation of $\mathrm{Zn}$ in p-type to intrinsic $\mathrm{Si}$.

It has been reported $[4,9]$ that annealing of $\mathrm{Zn}$-diffused dislocation-free samples at $873 \mathrm{~K}$ for $20 \mathrm{~min}$ leads to reproducible spreading-resistance profiles that can be attributed to $\mathrm{Zn}_{s}$. After applying this electrical-activation treatment to the $\mathrm{Zn}$-diffused p-type $\mathrm{Si}$ we find the levels $\mathrm{A} 1, \mathrm{ZnX} 1$ and $\mathrm{ZnX} 2$ beside the double acceptor response of $\mathrm{Zn}_{s}$ as shown in figure 5. $\mathrm{ZnX} 1$ and $\mathrm{ZnX} 2$ have been 
detected previously in silicon after Zn diffusion [12] and are considered to arise from complex formation of $\mathrm{Zn}$ with $\mathrm{H}$. By varying the pulse voltages in the DLTS measurements we found that several $\mu \mathrm{m}$ from the contact the concentrations of $\mathrm{ZnX} 1$ and $\mathrm{ZnX} 2$ vary substantially with depth but that the sum of the concentrations is approximately constant. We conclude that $\mathrm{ZnX} 1$ and $\mathrm{ZnX} 2$ are introduced in the process of preparing the Schottky contacts, probably during chemical etching. The level A1 is reported to be a $\mathrm{Zn}-\mathrm{B}$ complex [8] that forms upon cooling. Assuming that only one $\mathrm{Zn}$ atom is involved in each of the complexes, the sum of the $\mathrm{Zn}$-related concentrations from DLTS, solid symbols in figure 6, equals the $\mathrm{Zn}_{s}$ concentration obtained by SRP. This implies that $\mathrm{Zn}_{s}$ is immobile during the quenching process and the subsequent anneal at $873 \mathrm{~K}$. No DLTS peak shows any correlation with $\mathrm{Zn}_{i}$ in its depth distribution. We can exclude that the majority of the Zn-related complexes like A1, observed by DLTS, form already at the diffusion temperature as this would affect the diffusion process. The observation that for DLTS and SRP essentially the same total zinc concentrations at a given penetration depth are obtained supports the view that complex formation preferentially takes place during quenching.

$\mathrm{Ni}$ is known to be a fast interstitial diffusor in Si [10] and at $873 \mathrm{~K}$ its solubility determined by $\mathrm{Ni}_{i}$ is as high as $3 \times 10^{14} \mathrm{~cm}^{-3}$. After Ni diffusion into already $\mathrm{Zn}$-doped samples none of the $\mathrm{Zn}$-correlated defects A1, ZnX1, ZnX2 or $\mathrm{Zn}_{s}$ are detected by DLTS (figure 7(a)). Moderate annealing at $400 \mathrm{~K}$ reactivates $\mathrm{Zn}$ only if a $4 \mathrm{~V}$ reverse bias voltage is applied to the Schottky contact (figure 7(b)). The peaks shown in figure 7 can be assigned to $\mathrm{ZnX} 1, \mathrm{ZnX} 2$ and $\mathrm{Zn}_{s}$ within the pertaining error limits. Comparing the various peak heights in figure 7(a) to those in figure 7(b) we may conclude that the concentration ratios of $\mathrm{ZnX} 1, \mathrm{ZnX} 2$ and $\mathrm{Zn}_{s}$ has changed somewhat. This is probably due to enhanced complex formation of $\mathrm{H}$ with the substitutional $\mathrm{Zn}_{s}$. The Fermi level which is otherwise close to the valence band in the p-type sample is raised in the presence of the reverse voltage. This Fermi level dependence of the stability of the $\mathrm{Zn}-\mathrm{Ni}$ complexes can be understood in the following framework.

We have calculated the total energies of $\mathrm{Zn}_{s}, \mathrm{Zn}_{i}, \mathrm{Ni}_{s}$ and $\mathrm{Ni}_{i}$ in $\mathrm{Si}$ as well as for several aggregates including the trigonal and orthorhombic $\mathrm{Zn}_{s}-\mathrm{Ni}_{i}$ pairs using the linear muffin-tin orbitals method [13]. For isolated $\mathrm{Zn}_{s}$ we obtain two acceptor levels, $E^{0 /-}=E_{v}+0.22 \mathrm{eV}$ and $E^{-/ 2-}=E_{v}+0.35 \mathrm{eV}$. The numerical values are somewhat smaller than the experimental data in table 1; however, the differences do not alter the qualitative discussion below. If we consider pairs of $\mathrm{Zn}_{s}$ and $\mathrm{Ni}_{i}$, the only combination with a significant binding energy is a trigonal pair where the two partners are one nearest neighbour distance apart. The resulting total energies for the trigonal $\mathrm{Zn}_{s}-\mathrm{Ni}_{i}$ pair are shown in figure 8 as a function of the Fermi level position in comparison with the sum of the total energies of the isolated $\mathrm{Zn}_{s}$ and $\mathrm{Ni}_{i}$ point defects. According to our calculation the pair has a shallow donor level at $E^{+/ 0}=E_{v}+0.05 \mathrm{eV}$ and two acceptor levels at $E^{0 /-}=E_{v}+0.55$ and $E^{-/ 2-}=E_{v}+0.65 \mathrm{eV}$. None of these levels would be observable by our DLTS experiment. A pair binding energy of $E_{b} \cong 1 \mathrm{eV}$ for p-type material is consistent

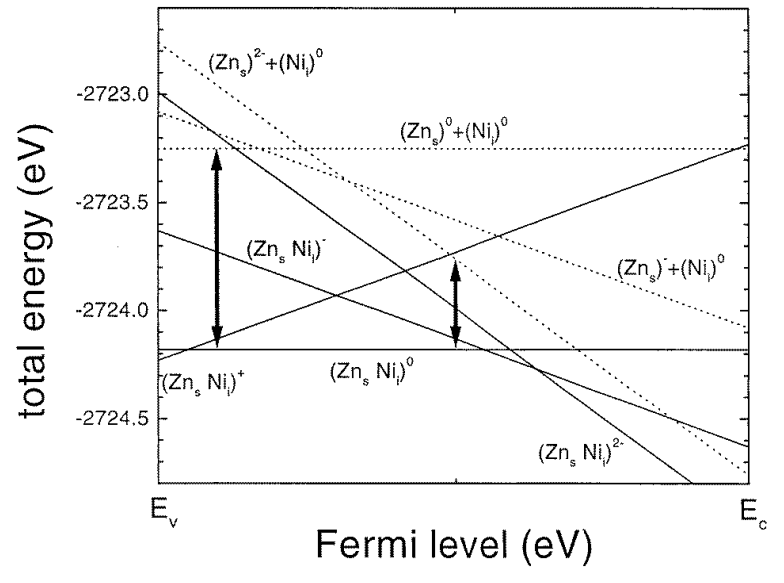

Figure 8. Total energies calculated for $\mathrm{Zn}_{s}$ and $\mathrm{Ni}_{i}$ and $\mathrm{Zn}_{s}-\mathrm{Ni}_{i}$ complexes in various charge states. Arrows for both p-type and intrinsic Si indicate the energy differences (binding energies) between the most stable configuration of the isolated defects and the complex.

with the experimental finding that the pairs do not dissociate at room temperature. For intrinsic and n-type samples the pair binding energy is $0.3 \mathrm{eV}$, which is not sufficient to prevent dissociation during reverse bias annealing. According to our calculation there is no ionization level $\mathrm{Ni}_{i}$ (see also [14]). Experimentally the $\mathrm{Ni}_{i}^{+}$spin state has been observed [15]. Our computational scheme fails to reproduce a $(+/ 0)$ donor level because it is very close to $E_{v}$. The same reason prevents detection by DLTS as well. Thus the formation of trigonal $\mathrm{Zn}_{s}-\mathrm{Ni}_{i}$ in p-type samples explains that according to DLTS there are no defect-related gap states in the lower half of the gap as long as there is a surplus of $\mathrm{Ni}_{i}$.

The results are shown in figure 8 as a function of the Fermi level for various charge states of the defects. The binding energy and therefore the tendency to form $\mathrm{Zn}-\mathrm{Ni}$ complexes is greatly enhanced in the case of low Fermi levels, i.e. in p-type Si. This explains differences in the concentration profiles from DLTS on p-type Si and SRP on near-intrinsic $\mathrm{Si}$ in figure 4 , assuming that $\mathrm{Ni}_{i}$ is involved in complex formation with $\mathrm{Zn}_{s}$ upon cooling from the diffusion temperature. The Fermi level dependence of the stability of the complex is also in agreement with DLTS results after a moderate heat treatment with and without bias voltage shown in figures 7(a) and 7(b). A reverse bias voltage raises the Fermi level and therefore allows for the dissociation of the $\mathrm{Zn}-\mathrm{Ni}$ complex at $400 \mathrm{~K}$. At this temperature the mobility of $\mathrm{Ni}$ is expected to be similarly high as that of $\mathrm{Cu}_{i}$, implying that the impurity can drift away from the $\mathrm{Zn}$ atom $[1,16]$. The $\mathrm{Zn}-\mathrm{Ni}$ complex is stable against dissociation without the presence of a bias voltage.

\section{Conclusions}

Our findings strongly support that $\mathrm{Zn}$ is predominantly incorporated on substitutional sites after in-diffusion from the vapour phase and subsequent quenching. Dislocations in plastically deformed $\mathrm{Si}$ serve as sinks for $\mathrm{Si}_{i}$ and unwanted impurities. This favours incorporation as isolated $\mathrm{Zn}_{s}$ atoms, which is not hampered by the generation of excess 
self-interstitials during the kick-out diffusion process. In dislocation-free $\mathrm{Si}, \mathrm{Zn}_{s}$ may be passivated and an additional annealing step at $873 \mathrm{~K}$ is required to electrically activate this defect state. $\mathrm{Zn}_{s}$ is immobile during this second annealing step. Deliberate contamination of $\mathrm{Zn}$-diffused samples with Ni has shown that Ni is a likely candidate for the passivation of $\mathrm{Zn}$ during quenching. We note, however, that preliminary experiments with $\mathrm{Cu}$ as contaminant reveal similar passivation behaviour. The binding energies of $\mathrm{Zn}-\mathrm{Ni}$ complexes decrease with increasing Fermi level and therefore passivation of $\mathrm{Zn}$ by $\mathrm{Ni}$ is more likely to occur in p-type $\mathrm{Si}$. Future diffusion experiments should utilize either chlorineflushed resistance furnaces or lamp-based heating in order to reduce transition metal contaminations.

\section{References}

[1] Landolt-Börnstein New Series 1998 Group III, vol 33, ed D L Beke (Berlin: Springer) subvolume A, pp 1-257

[2] Perret M, Stolwijk N A and Cohausz L 1989 J. Phys.: Condens. Matter 16347
[3] Stolz P, Pensl G, Grünebaum D and Stolwijk N A 1989 Mater. Sci. Eng. B 431

[4] Bracht H, Stolwijk N A and Mehrer H 1995 Phys. Rev. B 52 16542

[5] Bracht H 1993 PhD Thesis Münster pp 46-9

[6] Lannoo M and Bourgoin J 1981 Point Defects in Semiconductors I (Berlin: Springer)

[7] Humphreys R G 1981 J. Phys. C: Solid State Phys. 142935

[8] Hermann J M III and Sah C T 1972 Phys. Status Solidi a 14 405

[9] Weiss S, Beckmann R and Kassing R 1990 Appl. Phys. A 50 151

[10] Weber E R 1983 Appl. Phys. A 301

[11] Bracht H and Overhof H 1996 Phys. Status Solidi a 15847

[12] Bracht H, Stolwijk N A, Mehrer H and Yonenaga I 1993 Phys. Status Solidi a 137499

[13] Gunnarson O, Jepsen O and Anderson O K 1983 Phys. Rev. B 277144

[14] Beeler F, Andersen O and Scheffler M 1990 Phys. Rev. B 41 1603

[15] Ludwig G W and Woodbury H H 1962 Solid State Physics: Advances in Research and Application vol 13, ed F Seitz and D Turnbull (New York: Academic) p 223

[16] Heiser T and Mesli A 1993 Appl. Phys. A 57325 